\title{
SEXUALIDADE HUMANA NA FORMAÇÃO DO ENFERMEIRO
}

\author{
Elucir Gir* \\ Maria Suely Nogueira** \\ Nilza Tereza Rotter Peláa**
}

GIR, E.; NOGUEIRA, M.S.; PELÁ, N.T.R. Sexualidade humana na formação do enfermeiro. Rev.latinoam.enfermagem, Ribeirão Preto, v. 8, n. 2, p. 33-40, abril 2000.

Aplicou-se um questionário aos alunos do curso de graduação em Enfermagem, com o objetivo de se verificar as noções que estes sujeitos apresentam acerca da temática sexualidade, no término do curso de graduação, bem como identificar alguns temas da sexualidade vivenciados por ocasião de suas atividades acadêmicas. Os resultados mostraram que os alunos apresentam, em sua maioria, noções fluidas e limitadas, sem embasamento norteador sobre sexualidade humana, além de empregarem os termos "sexo" e "sexualidade" como sinônimos. Os alunos referem ter necessidade de adquirir conhecimento sobre sexualidade. Apresenta-se, ainda, a classificação do embasamento recebido, as disciplinas do curso de graduação que viabilizaram discussões e as situações-tema enfrentadas ou abordadas nas atividades acadêmicas.

UNITERMOS: sexualidade, estudantes, enfermagem

\section{INTRODUÇÃO}

Seria utópico querer abordar sexualidade humana do ponto de vista isolado, por ser um processo contínuo que se inicia na concepção e que percorre todo o ciclo da vida, recebendo influência direta e constante de múltiplos fatores, tais como o biológico, fisiológico, emocional, social e cultural.

As experiências sexuais e aprendizagem social adquiridas repercutem fortemente na vida de um ser, e de maneira recíproca a sexualidade tem potencial para interferir nos aspectos social e psicológico, ao longo desta trajetória, simultaneamente ao desenvolvimento e crescimento do indivíduo.

Discutir sexualidade humana, há algumas décadas, era assunto difícil, pois o referencial teórico específico era escasso na literatura. Historicamente, o seu estudo só passou a ser reconhecido e incrementado a partir da década de 60. O embasamento científico originou-se com os trabalhos pioneiros de Henry H. Ellis (1859-1939) e Sigmund Freud (1856-1936) que, na época, foram censurados, criticados e rejeitados. Outros pesquisadores, como Alfred Kinsey (1894-1956), realizaram investigações sobre o comportamento sexual dos americanos.

Em 1966, MASTERS \& JOHNSON iniciaram estudos sobre os aspectos fisiológicos da resposta sexual humana e, posteriormente, KAPLAN (1978, 1979) realizou estudos essenciais para quem estuda a temática sexualidade. Hoje observa-se uma produção científica em ascensão, apesar deste aspecto isolado não oferecer base para o profissional de saúde exercer suas atividades concernentes ao assunto.

Mesmo com o avanço científico e tecnológico das últimas décadas, nota-se que a evolução não se processa de maneira homogênea sendo sexualidade um tema impregnado de mitos, preconceitos e desconhecimentos para muitas pessoas. É assunto que se reveste de massa compacta de contradições, tabus e ignorância, a tal ponto que nos dias atuais muitas pessoas consideram este tema como exclusivo para adultos e defendem a idéia de que tal referencial deve ser excluído

\footnotetext{
* Professor Associado junto ao Departamento de Enfermagem Geral e Especializada da Escola de Enfermagem de Ribeirão Preto da Universidade de São Paulo

** Professor Doutor junto ao Departamento de Enfermagem Geral e Especializada da Escola de Enfermagem de Ribeirão Preto da Universidade de São Paulo

*** Professor Titular junto ao Departamento de Enfermagem Geral e Especializada da Escola de Enfermagem de Ribeirão Preto da Universidade de São Paulo
} 
dos âmbitos de palestras, cursos e currículos escolares, por considerarem-no obsceno. Críticas negativas são feitas quando alguma cena erótica é exibida em filmes e os pais, geralmente, utilizam a "técnica do silencio" ou da "mentira" com o seu filho, principalmente quando emerge algum questionamento sobre o assunto (VITIELLO \& RODRIGUES JUNIOR, 1997).

Sexualidade é um tema ainda muito reprimido pela nossa sociedade e a repressão na educação sexual, desde a infância, acarreta sucessivos nós que vão se emaranhando e provocando esmagamento do nosso desenvolvimento e comportamento sexual. Tal situação exige, em geral, um longo tempo para ser absorvida e nem sempre reverte-se espontaneamente e/ou liberta o indivíduo de sentimentos negativos, que foram incoerentemente introjetados.

Acredita-se que independentemente da forma como a sexualidade foi abordada na infância e adolescência do indivíduo, a escola ou a universidade não podem omitir ou marginalizar a discussão do processo da sexualidade humana, se realmente objetiva que esses alunos tenham uma visão holística do homem, quer para sua atuação enquanto profissional, quer para sua autocompreensão, enquanto ser-de-relação.

A enfermagem insere-se dentro deste contexto sócio-cultural e, portando, dele não difere quanto às crenças, mitos e tabus.

LEWIS \& BOR (1994) pesquisaram, através de questionários distribuído a enfermeiros, a correlação entre conhecimento, conduta e práticas de enfermagem no contexto da sexualidade humana e encontraram: $54 \%$ dos sujeitos estudados sentiram-se embaraçados em discutir sexualidade humana; $64 \%$ raramente ou nunca questionaram sobre a sexualidade do paciente; entretanto, $54 \%$ deles acreditam ser relevante incluir questões sobre a história sexual do paciente em sua ficha de admissão.

PELÁ et al. (1995) realizaram estudo em um hospital-escola onde aplicaram questionário para avaliar o conhecimento que 147 enfermeiros possuíam sobre sexualidade, na assistência ao paciente como "ser sexual". O resultado desta pesquisa mostrou que apenas $25 \%$ dos profissionais estudados tinham conteúdo sobre sexualidade humana em sua formação acadêmica, conseguindo orientar e esclarecer seus pacientes sobre questões sexuais.

Preocupados com esta questão e considerando que o processo de sexualidade humana fora abordado na disciplina de graduação "Enfermagem em Doenças Transmissíveis", numa escola do interior paulista, através de aulas formais durante dois anos, um grupo de professores propôs-se a realizar um levantamento entre os alunos do último semestre de graduação em Enfermagem, para verificar as noções destes estudantes sobre a temática sexualidade, ao final do curso de graduação, e identificar alguns sub-temas desta temática, vivenciados por ocasião de suas atividades acadêmicas.

\section{METODOLOGIA}

Elaborou-se um questionário, composto por 6 questões, sendo 3 com respostas em aberto, 1 fechada e 2 mistas (Anexo 1). O referido instrumento foi submetido à avaliação de três juizes. Consideradas as sugestões quanto à forma redacional e estrutural, aplicou-se o mesmo aos alunos regularmente matriculados no último semestre do curso de graduação em Enfermagem de uma escola pública do interior do estado de São Paulo.

Dos 48 alunos matriculados no $8^{\circ}$ semestre do curso, somente $40(83,3 \%)$ alunos constituíram a amostra e os critérios estabelecidos para a seleção dos sujeitos foram:

- estar presente no dia pré-determinado pelos autores para a coleta de dados;

- aquiescer em participar, da pesquisa, enquanto sujeito; - responder ao questionário sem deixar questão em branco.

Os dados foram coletados num momento único, de maneira coletiva, em sala de aula, antes do início de uma aula teórica. Uma das autoras manteve contato prévio com a seção de graduação e com os professores responsáveis pela disciplina ministrada, na data definida, obtendo consentimento para a realização da investigação e para a coleta dos dados no início do período previsto para a aula.

Os autores orientaram os alunos quanto aos objetivos propostos e distribuíram o questionário a todos os presentes, facultando-lhes a possibilidade de participarem do estudo.

Os dados obtidos foram analisados através de porcentagem simples e apresentados em forma de tabelas.

\section{RESULTADOS E DISCUSSÃO}

Foram aplicados 48 questionários, e destes, 40 $(83,3 \%)$ foram devolvidos devidamente preenchidos.

As respostas da $1^{\text {a }}$ questão: "O que você entende por Sexualidade Humana?” encontram-se na Tabela 1, onde pode-se observar que as respostas atribuídas representam, em sua maioria, idéias fluídas e limitadas, sem embasamento teórico norteador. 
Tabela 1 - Distribuição numérica e percentual das respostas referentes à questão: "O que você entende sobre Sexualidade Humana?"

\begin{tabular}{|c|c|c|}
\hline Respostas & $\mathbf{n}^{0}$ & $F(\%)$ \\
\hline - Em branoo .. & 12 & 30,0 \\
\hline - É tudo relacionado a Sexo, relação sexual . & 06 & 15,0 \\
\hline -É urna forma de expressarseus impulsos sexuais.... & 03 & 7,5 \\
\hline - Relacionamento íntimo adois que ervolve amor..... & 02 & 5,0 \\
\hline -E uma necessidade para atirgir equilibrio ................ & 02 & 5,0 \\
\hline 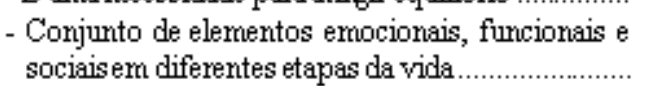 & 02 & 5,0 \\
\hline 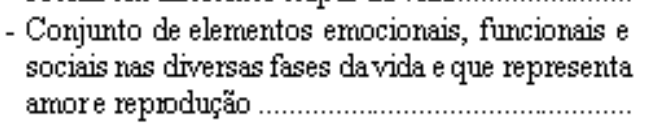 & 01 & 2,5 \\
\hline $\begin{array}{l}\text { - São fatores que interferem no relacio name nto } \\
\text { masculino ou fermininocomo seu próprio corpo..... }\end{array}$ & 01 & 2,5 \\
\hline - Coisa necessánia para aumentar a população .......... & 01 & 2,5 \\
\hline - Não sei ...................................................... & 02 & 5,0 \\
\hline 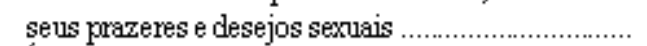 & 01 & 2,5 \\
\hline - É participação fisica, psiquica respeito ................... & 01 & 2,5 \\
\hline $\begin{array}{l}\text {-É sber entender o relacionamento do sexo oposto.. } \\
\text { - É o auto-conhecimento do corpo, é reação frente }\end{array}$ & 01 & 2,5 \\
\hline 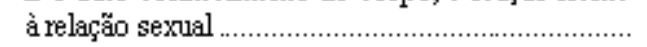 & 01 & 2,5 \\
\hline $\begin{array}{l}\text { - Necessidade de todo ser humano para preservar a } \\
\text { espécie e consumar o amor edar satisfação ............ }\end{array}$ & 01 & 2,5 \\
\hline $\begin{array}{l}\text { - Corgunto de padrões, comportamentos e conoeitos } \\
\text { morais }\end{array}$ & 01 & 2,5 \\
\hline $\begin{array}{l}\text { - Potencial comum de todos os individuos e que } \\
\text { sofrem influências intemas e extemas dos fatores } \\
\text { biológicos, psicológicos, sociais, políticos e }\end{array}$ & & \\
\hline 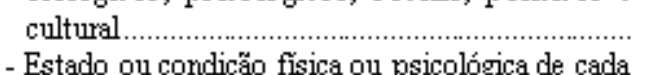 & 01 & 2,5 \\
\hline 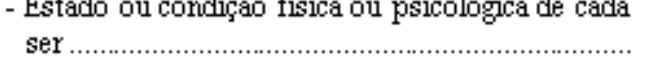 & 01 & 2,5 \\
\hline TOTAL & 40 & (100) \\
\hline
\end{tabular}

As respostas mostram uma diversidade de significados atribuídos ao entendimento sobre sexualidade humana, sendo algumas apenas relacionadas à reprodução e sensações instintivas. Um total de 12 alunos $(30,0 \%)$ deixaram-na em branco e $2(5,0 \%)$ referiram não saber. Grande número de respostas revelou o componente "amor" vinculado à sexualidade.

$\mathrm{Na}$ literatura, sexualidade humana é descrita de diversos modos, dependendo das crenças e (pre)conceitos do autor. Mas, apesar da possibilidade das definições serem limitadas ou possuírem múltiplas facetas há um denominador comum em todas as definições, que é o reconhecimento de que sexualidade é uma parte intrínseca do nosso ser (HOGAN, 1980).

Sexualidade no seu sentido amplo pode ser definida como um aspecto profundo e penetrante da personalidade total, a soma geral dos sentimentos e comportamentos de alguém, não somente como um ser sexual, mas como um homem ou mulher (SUTTERLEY
\& DONNELY, 1973).

Para HOGAN (1980), a sexualidade é um processo complexo e intrínseco do ser e que extrapola o conceito de se caracterizar um fenômeno biológico, com a finalidade de diferenciar o macho da fêmea.

Em algumas respostas evidencia-se que o signo "sexo" é empregado como parte integrante da sexualidade, cabendo aqui ressaltar que, apesar de sexo e sexualidade envolverem aspectos comuns e até serem utilizados como se fossem sinônimos, são termos distintos.

De acordo com FERREIRA (1979), sexo é a "conformação particular que distingue o macho da fêmea, nos animais e nos vegetais; atribuindo-lhes um papel determinado na geração e conferindo-lhes certas características distintas" (p.1296); "Sexualidade é a qualidade de sexual, conjunto de todos os fenômenos da vida sexual" (p.1297).

Para HOGAN (1980), sexualidade é muito mais do que o ato sexual em si, pois sexo conota um ato fisiológico e sexualidade a totalidade do ser humano.

Quando os sujeitos desta investigação referem que sexualidade humana é uma "coisa necessária para aumentar a população", "é necessidade de todo ser humano para preservar a espécie e consumar o amor e dar satisfação", "é conjunto de padrões, comportamentos e conceitos morais", percebe-se que estas respostas revelam que, ainda em nossos dias, as pessoas têm diferentes concepções acerca da sexualidade humana.

Segundo MATTARAZZO (1985), na história da sexualidade existem 5 padrões culturais que podem ser apresentados numa escala, apontando diversos significados do sexo para diferentes pessoas.

Nível 1: Sexo como algo ruim e pecaminoso. Deve ficar restrito.

Nível 2: Sexo é bom, mas só deve existir depois do casamento e tem a finalidade de procriação.

Nível 3: Sexo não é bom nem ruim, depende das circunstâncias e conseqüências.

Nível 4: Sexo é bom em si mesmo e não depende de nada. Vale o momento, o aqui e agora.

Nível 5: Anarquia sexual, onde tudo é válido. Sexo livre.

Quanto à questão "Você acha necessário o enfermeiro adquirir conhecimento sobre sexualidade?", 38 alunos (95\%) responderam que sim e 02 (5\%) aludiram não saber. Com base na justificativa destas respostas, montou-se a Tabela 2, onde observa-se coerência dos respondentes quanto à necessidade de embasamento para tratar do assunto durante a formação acadêmica do enfermeiro. 
Tabela 2 - Distribuição numérica e percentual das razões pelas quais o enfermeiro deve adquirir conhecimento sobre sexualidade, segundo os alunos de graduação

\begin{tabular}{|c|c|c|}
\hline Respostas & $\mathbf{n}^{\mathrm{a}}$ & $\mathbf{F}(\%)$ \\
\hline \multicolumn{3}{|l|}{ - Para discutir e resolver as situações que surgirem } \\
\hline 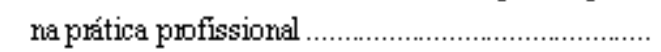 & 17 & 42,5 \\
\hline - Porque o ser humano não se dissocia da sua & & \\
\hline sexualidade e a enfermeira trata como um todo...... & 07 & 17,5 \\
\hline - Para exercer seguramente o papel de educadora ........ & 06 & 15,0 \\
\hline - Para ter auto-conhecimento e promover educação & & \\
\hline do pxiente & 05 & 12,5 \\
\hline 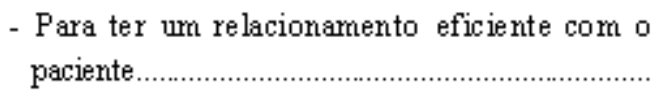 & 02 & 5,0 \\
\hline $\begin{array}{l}\text { - Para o enfermeiro poder responder perguntas dos } \\
\text { pacientes e proferir palestras, resolver dúvidas e }\end{array}$ & & \\
\hline 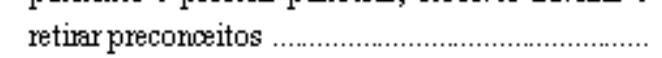 & 01 & 2,5 \\
\hline - Para lidar com saúde da população e sexualidade é & & \\
\hline 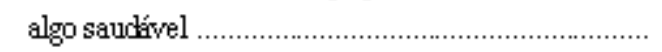 & 01 & 2,5 \\
\hline 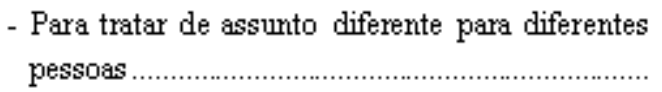 & 01 & 2,5 \\
\hline TOTAL & 40 & (100) \\
\hline
\end{tabular}

Dentre o conjunto de respostas atribuídas (Tabela 2) tem-se que 17 estudantes (42,5\%) têm convicção da necessidade de obterem conhecimento sobre sexualidade para utilizarem-no na prática profissional da saúde; 07 $(17,5 \%)$ consideram que sexualidade é parte integrante do ser humano, não podendo ser dissociada; 06 (15,0\%) revelaram a preocupação em exercer o papel de educador com segurança. Estes dados assemelham-se aos encontrados por LEWIS \& BOR (1994) e PELÁ et al. (1995). Percebe-se que os alunos, de maneira geral, consideram o conhecimento fundamental para a qualidade da assistência ao paciente/cliente, independente da sua patologia ou motivo da internação.

A questão "Você já vivenciou alguma situação acadêmica que exigiu seu conhecimento sobre o assunto?" obteve 29 respostas afirmativas (72,5\%), 10 negativas $(25 \%)$ e 1 aluno $(2,5 \%)$ não fez nenhuma alusão.

Ao serem questionados a explicitarem uma destas situações, 24 alunos (60,0\%) não exemplificaram nenhuma delas. Os demais $16(40,0 \%)$ citaram um ou mais temas de situações vivenciadas, quer através de questionamentos em palestra ou em diálogos durante assistência de enfermagem, o que totalizou 38 sujeitos (Tabela 3).
Tabela 3 - Distribuição numérica e percentual de temáticas vivenciadas em situações acadêmicas

\begin{tabular}{|c|c|c|}
\hline Respostas & & \\
\hline - Sexo e gravidez & 08 & 21,05 \\
\hline - Orgasmo ............. & 04 & 10,53 \\
\hline - Sexoe puerpério. & 04 & 10,53 \\
\hline 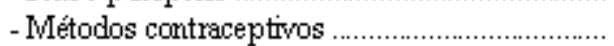 & 04 & 10,53 \\
\hline - Relacionamento sexual & 04 & 10,53 \\
\hline - Prazer sexuale preocupação estéticacorporal.... & 03 & 7,89 \\
\hline - Masturbação & 03 & 7,89 \\
\hline 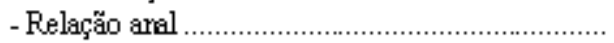 & 02 & 5,26 \\
\hline - Mulher frígida - usada pelo marido como & 01 & 2,63 \\
\hline -Dispareuria. & 01 & 2,63 \\
\hline -Impotênci sexual. & 01 & 2,63 \\
\hline - Alterações oorporais .... & 01 & 2,63 \\
\hline - Sexo e paraplegia .......... & 01 & 2,63 \\
\hline - Posipões sexuais .. & 01 & 2,63 \\
\hline TOTAL & 38 & 100,0 \\
\hline
\end{tabular}

"Como você se sentiu quando teve que abordar sexualidade com um paciente?" foi a quarta pergunta formulada. Houve 54 respostas para esta questão, visto que os alunos atribuíram de uma a três respostas para a mesma o que fez aumentar o total da amostra. As respostas foram classificadas em três grupos (Tabela 4), ou sejam, as que denotam comportamentos positivos e desejados estão representadas por *, reações negativas e indesejadas $\triangle$, respostas neutras ${ }^{\circ}$. Pelo exposto, observase que a maioria das reações referidas correspondem a comportamentos negativos, seguidos por positivos e neutros.

Tabela 4 - Distribuição numérica das respostas referentes como o aluno se sentiu ao ter que abordar sexualidade com o paciente

\begin{tabular}{|c|c|c|}
\hline Respostas & & \\
\hline * Natural & 11 & 20,37 \\
\hline - Insegura.. & 08 & 14,81 \\
\hline - Faltade embasamento .......... & 08 & 14,81 \\
\hline${ }^{\circ}$ Em branco. & 06 & 11,11 \\
\hline * Segura .......... & 05 & 9,26 \\
\hline - Constrangica... & 04 & 7,41 \\
\hline - Despreparada.. & 02 & 3,70 \\
\hline "Não passei por nertuma experiência . & 02 & 3,70 \\
\hline • Ansiosa ................ & 01 & 1,85 \\
\hline - Apreensiva. & 01 & 1,85 \\
\hline 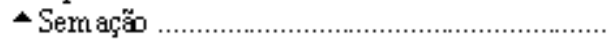 & 01 & 1,85 \\
\hline 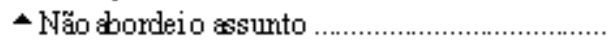 & 01 & 1,85 \\
\hline * Difícil no início ... & 01 & 1,85 \\
\hline - Dificuldade como sexo masculino ...................... & 01 & 1,85 \\
\hline 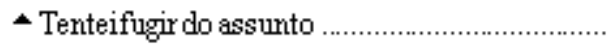 & 01 & 1,85 \\
\hline 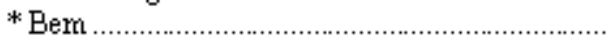 & 01 & 1,85 \\
\hline TOTA & & 100 \\
\hline
\end{tabular}


Se observarmos todas as respostas negativas, verificaremos que elas remetem à questão de despreparo não só cognitiva, como de treino específico para lidar com a situação. Mas quem os prepararia? Os professores de enfermagem também não carecem de formação para isto? As repostas para estas questões encontram-se a seguir, quando os alunos discorrem sobre o preparo recebido.

Assim, manifestaram-se, os sujeitos quanto ao embasamento sobre sexualidade obtido no curso de graduação; 25 alunos $(56,8 \%)$ referiram ter considerado o ensino insuficiente, $9(20,45 \%)$ classificaram-no como regular, $3(6,8 \%)$ péssimo, $2(4,54 \%)$ bom e $1(2,27 \%)$ aluno não fez nenhuma alusão.

Quanto às disciplinas que fazem parte do elenco do curso de graduação, ministrado a estes sujeitos e que ofereceram alguma noção ou embasamento sobre sexualidade, destacam-se: Ginecologia referida 29 vezes; Obstetrícia: 26; Psicologia: 16; Saúde Pública e Psiquiátrica: 7; Enfermagem Médica, Anatomia e Fisiologia: 6 e Saúde do Escolar: 1. Seis sujeitos deixaram em branco esta questão.

EGRY (1985), investigando o ensino da sexualidade humana, em 1984 e 1985 em uma escola de enfermagem estadual na capital paulista, mostrou a inexistência da temática na estrutura curricular, a ausência de preocupação em ministrar este ensino e, ainda, a incapacidade dos docentes investigados para assumirem tal responsabilidade. Neste estudo ficou evidenciada também a ansiedade dos docentes para superarem as incapacidades e para habilitarem-se a fim de proporcionar um ensino de enfermagem mais crítico, mais consciente. Nesse sentido duas alternativas emanaram a partir dos sujeitos participantes da pesquisa, ou seja: "Ao tomarmos maior consciência da nossa própria sexualidade nas suas dimensões, habilitamo-nos à mudança de atitude - mais aberta - perante os alunos e iniciamos com eles um diálogo mais franco e honesto; a segunda refere-se à busca de aquisição de conhecimentos profundos e específicos através da leitura, discussão e reflexão, que nos capacita a procurar, em conjunto com os alunos, as soluções para os problemas que ocorrem no dia-a-dia de nossas relações não só com os clientes, mas também com outras pessoas que nos afetam" (p.124-5). Entendem ainda que a não inclusão explícita da temática "sexualidade humana" nos currículos mínimos de enfermagem constituiu-se uma omissão histórica, tradicionalista e moralista.

O enfermeiro é um profissional que tem oportunidade de se deparar com os grupos mais variados de pessoas - crianças, adolescentes, adultos e idosos, em situações diversas de saúde ou doença, em nível da comunidade, ambulatorial ou hospitalar. Independente de sexo, cor, raça e nível sócio-econômico e cultural, o indivíduo deve ser visto como um todo.
Quando se fala no todo do sistema-homem, não se pode separar a sexualidade dos seus outros processos, pois como refere HOGAN (1980), sexualidade é parte intrínseca do ser e que está presente em todas as etapas do ciclo da vida, sob diferentes manifestações.

Para que estas manifestações sejam distingüidas entre o normal e o patológico, e mesmo para haver uma abordagem concernente ao assunto, é necessário que o enfermeiro tenha embasamento suficiente do processo de sexualidade, nas diferentes etapas do ciclo da vida, e conheça as conseqüências advindas das enfermidades. Nesta situação, o paciente enfrenta problemas novos que rotineiramente requerem ajuda de outros para uma solução.

Tem-se presenciado, no desenvolver das atividades de alguns profissionais da área de saúde, dificuldade no desempenho de um papel desejável na abordagem da sexualidade. Analisar o comportamento do indivíduo, responder a questionamentos, orientar o paciente quanto a possíveis efeitos colaterais de medicamentos, que interferem na sexualidade, e sobre a doença em si, são algumas das situações que o enfermeiro enfrenta e, ao tentar abordar este aspecto, deixa transparecer dúvida, dificuldade, insegurança e, quando não, fuga.

Cabe ao enfermeiro realizar educação sexual, mas por ser este um tema muito amplo, devem ser considerados os sub-itens abaixo:

- resposta sexual humana;

- aspectos biológicos, sociais, culturais, psicológicos que envolvem a sexualidade;

- aspectos da sexualidade nas diferentes etapas do ciclo vital;

- diversidade das práticas sexuais;

- comportamento sexual de risco, vulnerabilidade social, redução de danos;

- disfunções sexuais (anorgasmia, disfunção erétil, ejaculação precoce, dispaurenia e vaginismo);

- sexualidade em determinadas situações fisiológicas: gravidez, puerpério, planejamento familiar;

- sexualidade em situações de doença: cardiopatia, diabetes, ostomias, cirurgias mutiladoras;

- sexualidade e métodos contraceptivos;

- sexualidade e aborto;

- prevenção e controle de doenças sexualmente transmissíveis - abordando aspectos de higiene, uso de preservativos, bem como as conseqüências advindas com promiscuidade e hábitos de vida sexual perigosos e modo de transmissão de doenças.

Além disso, o enfermeiro deve estar alerta às alterações emocionais que podem ser desencadeadas. A atuação do enfermeiro não deve ser somente no hospital, mas deve expandir-se a creches, escolas, indústrias, empresas. A função educativa do enfermeiro é bastante 
ampla e deve ser direcionada ao indivíduo, família e comunidade.

Em muitas situações, ele deve tratar do assunto buscando auxílio junto a outros profissionais: psicólogo, médico, sexólogo, pois este deve ser um trabalho multiprofissional.

Sabe-se que é comum o paciente procurar o seu médico de clínica geral para abordar seus problemas sexuais, pois, na maioria das vezes, desconhece qual o profissional mais adequado para tratar deste assunto. $\mathrm{O}$ enfermeiro, profissional capaz de desenvolver também tais atividades, precisa habilitar-se nesse sentido, a fim de assumir estes deveres que cabem a ele.

BARTSCHER (1983) menciona algumas situações onde a informação sexual deve ser rotineiramente acrescentada à prestação de cuidados ao paciente:

- "cirurgia cardíaca - há freqüentemente dúvidas se a atividade sexual será ou não permitida;

- hipertensão - muitas medicações afetam a potência erétil, capacidade ejaculatória e a intensidade do clímax;

- diabetes - a incidência da impotência é muito mais acentuada nos diabéticos homens e a lubrificação vaginal é diminuída ou ausente em muitas mulheres;

- desordens do sistema nervoso, tais como Parkinson, esclerose múltipla, lesão da medula espinhal - onde são necessárias adaptações para que estes indivíduos tenham uma relação mais saudável;

- fase terminal - as necessidades sexuais freqüentemente persistem, e eles precisam de alguém que entenda isto e os ajude;

- idoso - culturalmente, tende-se a acreditar que a dimensão sexual do idoso tenha se esgotado ao longo de seu processo de vida. Esta crença leva profissionais e familiares a reprimir manifestações de sexualidade dos idosos, com mais ênfase nas mulheres;

- dependentes de produtos químicos - uso de álcool, por exemplo, faz com que a pessoa tenha desejos sexuais, mas não consiga realizá-los;

- cronicamente doente - muitos sedativos, antidepressores, anti-espasmódicos e hormônios podem interferir na resposta sexual".

O enfermeiro deve empregar esforços para que a educação sexual seja inserida no plano geral da educação, podendo, na faculdade, refletir e discutir o tema em níveis mais profundos e objetivos. TAVARES (1985) considera que o enfermeiro seja o profissional mais indicado para desempenhar função de orientador sexual no ensino básico. Porém, investigando enfermeiros, PELÁ et al. (1995) detectaram que eles possuem conhecimentos e habilidades insuficientes para trabalhar a questão.

De maneira similar, SILVEIRA (1993), avaliando o grau de conhecimento sobre sexualidade entre alunos de medicina e de engenharia, verificou que ambos apresentam níveis semelhantes de conhecimento, no período final do curso de graduação. Estes dados surpreendem, pois os profissionais da saúde devem assistir o indivíduo de maneira global, como um ser sexuado.

Se o enfermeiro enfrenta situações embaraçosas, o aluno de enfermagem, principalmente os principiantes, muito mais, pois ao levantarem a história do paciente eles não abordam sexualidade, referem sentir-se inseguros e com vergonha para fazê-lo, o que vem de encontro ao mencionado por BARTSCHER (1983). Esta autora menciona que a parte sexual referente à história da vida do paciente é vista como uma invasão da privacidade. Para que esta visão seja amenizada, ela sugere alguns aspectos práticos que podem ser seguidos para não traumatizarem os pacientes, a fim de que eles não bloqueiem o diálogo. São eles:

1. começar com tópicos mais gerais (menstruação) e progredir até os mais pessoais (vida sexual);

2. para aumentar o conforto do indivíduo, começar com termos gerais, como: "Muitas pessoas foram ensinadas..." ou "muitas pessoas hesitam em discutir..."

3. evitar linguagem vaga e termos não específicos;

4. checar que termos são familiares ao indivíduo;

5. não julgar nada "certo", "errado" ou "anormal";

6. dispor de tempo suficiente e privacidade para esta interação;

7. oferecer tempo para o indivíduo refletir antes de responder;

8. assegurar ao indivíduo que a informação coletada é confidencial.

O enfermeiro deve contribuir para que os mitos e preconceitos direcionados à sexualidade sejam suavizados e que o conhecimento geral da população sobre o assunto seja melhorado. Precisa, também, intervir neste assunto, para que o homem seja tratado como um ser holístico, com seus múltiplos processos interdependentes, que permeiam o ciclo da vida, dentre eles o da sexualidade. Para tanto, as instituições formadoras precisam comprometer-se a capacitar o aluno quanto a este conteúdo.

A atenção à sexualidade é de caráter multiprofissional, e o enfermeiro não pode mais adiar a sua parcela de responsabilidade. Portanto, o preparo e a formação do profissional precisam ser valorizados no que tange a esta temática.

Com o advento da AIDS, o estudo da sexualidade precisou ser incrementado, porém os currículos de graduação e pós-graduação não acompanharam este avanço; devem, no entanto disponibilizarem-se de carga horária suficiente para esta temática. Ademais, a experiência profissional na docência tem mostrado que os enfermeiros tratam os pacientes como seres assexuados e dificilmente abordam aspectos da dimensão sexual, e 
mesmo a influência da doença, da terapêutica e do emocional sobre o exercício da sexualidade (GIR, 1997).

A versão ideológica que domina a sexualidade precisa ser rompida e deixar de ser subestimada, pois sexualidade diverge de reprodução biológica e extrapola o exercício da genitalidade, constituindo-se num componente essencial do indivíduo, quer como profissional ou cliente/paciente.

\section{CONSIDERAÇÕES FINAIS}

$\mathrm{O}$ aluno de graduação em Enfermagem tem noções incorretas sobre sexualidade e vivencia diversas situações acadêmicas sobre a temática, durante a graduação. Deveria adquirir maior conhecimento sobre o processo de sexualidade nas diferentes etapas do ciclo vital, uma vez que, como profissional, poderá trabalhar com crianças, adolescentes, adultos e idosos em situações de saúde ou doença, na comunidade ou no hospital. Assim, o homem poderá ser tratado como um ser holístico, com seus múltiplos processos interdependentes, sendo a sexualidade um dos processos intrínsecos ao seu ser.

A aquisição de conhecimentos contribui para a minimização de posturas indevidas e inadequadas quando se depara com tal assunto, quer em termos de educação sexual, de detecção de alterações ou de prevenção de problemas.

Para tanto, as instituições formadoras precisam comprometer-se a capacitar o aluno nesta temática.

\section{HUMAN SEXUALITY IN NURSES' FORMATION}

A questionnaire was applied to undergraduate nursing students in order to verify the ideas on the sexuality theme they had absorbed from the notions they received in their nursing undergraduate program. Results showed that most of these students have slightly, limited and unbased notions concerning human sexuality. They also use the terms sex and sexuality as if they were synonyms. Therefore, authors concluded that these students need to acquire knowledge about sexuality and some professional situations experienced are also mentioned. They also discussed the type of knowledge received and which courses approach it during the program.

KEY WORDS: sexuality, students, nursing

\section{SEXUALIDAD HUMANA EN LA FORMACIÓN DEL ENFERMERO}

Se aplicó un cuestionario a los alumnos del curso de pre-grado en enfermería, en el término del mismo, con el objetivo de verificar las acciones que estos sujetos presentan acerca de la temática de sexualidad, y también identificar algunos temas de la sexualidad vividos en sus actividades académicas. Los resultados demostraron que los alumnos presentan, en su mayoría, nociones fluidas y limitadas, sin una base de orientación sobre la sexualidad humana, además de usar el término "sexo" y "sexualidad" como sinónimos. Los alumnos refieren necesidad en adquirir conocimientos sobre sexualidad. Se presenta, además, la clasificación del conocimiento previo recibido, las asignaturas del curso de pre-grado que permitieron discusiones y las situaciones-tema enfrentadas y/o abordadas en las actividades académicas.

TÉRMINOS CLAVES: sexualidad, estudiantes de enfermería

\section{ANEXO 1}

1. O que você entende sobre SEXUALIDADE HUMANA?

2. Você acha necessário o enfermeiro adquirir conhecimentos sobre SEXUALIDADE?

Por quê?

$$
\text { SIM ( ) Não ( ) Não sei ( ) }
$$

3. Você já vivenciou alguma situação acadêmica que exigiu seu conhecimento sobre o referido assunto?

$$
\operatorname{SIM}(\text { ) Não ( ) }
$$

Descreva suscintamente a situação:

4. Como você se sente/sentiu quando tem/teve que abordar "SEXUALIDADE" com um paciente?
5. Como você classificaria o embasamento sobre SEXUALIDADE adquirido durante o seu curso de graduação?

$$
\text { ótimo ( ) Regular ( ) péssimo ( ) _ _ ( ) }
$$$$
\text { bom ( ) Insuficiente ( ) suficiente ( ) }
$$

6. Quais disciplinas lhe oferecem alguma noção ou embasamento sobre o assunto?

\section{SUGESTÔES:}

OBSERVAÇÔES: 


\section{REFERÊNCIAS BIBLIOGRÁFICAS}

01. BARTSCHER, P.W. Human sexuality and implications for nursing intervention: a format for teaching. J. Nurs Educ., v. 22, n. 3, p. 123127, March 1983.

02. EGRY, E.Y. O docente de enfermagem e o ensino da sexualidade humana: ação educativa através da pesquisa participante. São Paulo, 1985. 157p.Tese (Doutorado) - Faculdade Saúde Pública, Universidade de São Paulo.

03. FERREIRA, A.B. de H. Novo dicionário da língua portuguesa. Rio de Janeiro: Nova Fronteira, 1979. $1499 \mathrm{p}$.

04. GIR, E. A sexualidade e a mulher portdora do vírus da imunodeficiência humana - tipo 1. Ribeirão Preto, 1997. 201p. Tese (Livre Docência) - Escola de Enfermagem de Ribeirão Preto, Universidade de São Paulo.

05. HOGAN, R.M. Human sexuality: a nursing perspective. USA: Appleton-Century - Crofts, 1980.

06. KAPLAN, H. A nova terapia do sexo. Rio de Janeiro: Nova Fronteira, 1978.

07. KAPLAN, H. O desejo sexual. Rio de Janeiro: Nova Fronteira, 1979. v. 2.
08. LEWIS, S.; BOR, R. Nurses' knowledge and attitudes toward sexuality and relationship of these with nursing practice. J. Adv. Nurs., v. 20, n. 2, p. 251-259, 1994.

09. MASTERS, W.H.; JOHNSON, V. Human sexual response. Boston: Little Brown, 1966.

10. MATTARAZZO, M.H. A sexualidade e o amor. Clin. Med., v. 3, n. 2, p. 16-22, março 1985.

11. PELÁ, N.T.R.; MELO, A.S.; SANTANA, V.M.S.; NHAMBA, AL. A sexualidade humana no contexto da assistência de enfermagem. Rev. Bras. Sex. Humana, v. 6, n. 1, p. 99-113, 1995.

12. SILVEIRA, M.T. Formandos de medicina: conhecimentos, comportamentos e atitudes frente a sexualidade. Goiânia, 1993. 244p. Dissertação (Mestrado) - Faculdade de Educação. Universidade Federal de Goiás.

13. SUTTERLEY, D.C.; DONNELLY, G.F. Perspectives in human development-nursing throught the life cycle. Toronto: Lippincott, 1973.

14. TAVARES, C.A. Orientação sexual para crianças e adolescentes: proposta para formação de enfermeiros como educadores sexuais. Rev. Paul. Enfermagem, São Paulo, v. 5, n. 1, p. 8-10, jan./ março 1985.

15. VITIELLO, N.; RODRIGUES JUNIOR, O.M.R. As bases anatômicas e funcionais do exercício da sexualidade. São Paulo: Iglu, 1997. 